\section{Una mujer en edad de ser valiente. Sobre Lo contrario de mirar, de Ana Pellicer Vázquez}

\author{
Stephanie Cortez-Conde
}

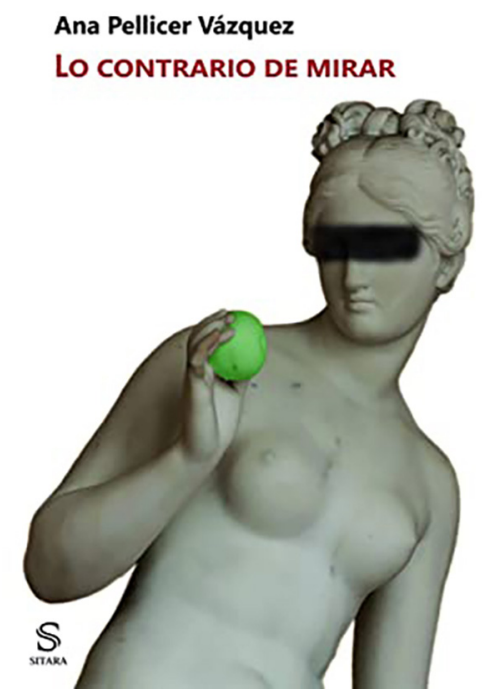

Ana Pellicer Vázquez, Lo contrario de mirar, ISBN: 978-84-17035-20-4, Madrid, Editorial Sitara, 2019, 176 pp.
U na fotografía, un museo, una cápsula del tiempo. Por mucho que ideemos mecanismos y herramientas cada vez más sofisticados para preservar la memoria, siempre quedará un glitch, algún vacío que sólo puede ser subsanado por la imaginación. Bajo esta premisa se desarrolla Lo contrario de mirar, el primer libro de la escritora española Ana Pellicer Vázquez, publicado por la editorial independiente Sitara como parte de la colección Fragua de Kulub. Sabemos, gracias a la autora, que la compilación estuvo bajo los cuidados de María José Bruña, Yuri Herrera y Andrés Neuman, quienes fungieron como sus principales correctores.

La obra se compone de catorce relatos que a su vez contienen varios microrrelatos. Estos últimos se nutren de una tradición que ha venido cultivándose en español por autores tan diversos como Juan José Arreola, Augusto Monterroso, Luisa Valenzuela y Ana María Shua.

Lo contrario de mirar navega entre la autobiografía ficcional, la crónica de viajes y la memoria como género literario. Esta hibridación genérica le permite a la autora abordar toda clase de temas desde una claridad que parece reservada al ensayo. Pienso, por ejemplo, en "Números", relato en el que se da a la tarea de narrar lo fantástico de lo cotidiano desplegando un catálogo de fechas aparentemente aleatorias, pero que yuxtapuestas anuncian un destino "trágicamente numérico" (72). ${ }^{1}$ Asimismo, a la narradora de este relato le interesa dejar en claro una cosa: la memoria es falible. Como consecuencia, acepta que cualquier intento por reconstruirla está condenado a incluir algo falseado. De modo que hay dos opciones: o cubrir la mentira o convertirla en recurso. Haciendo alarde de la desfachatez que otorga saberse portador de una verdad explosiva, la narradora opta por lo segundo y nos dice: "Hace trescientos millones de años, cuando los seres humanos comenzaron a mentir, su cerebro se expandió y evolucionó" (65).

Alguna vez leí que la figura de la flaneuse no gozaba del mismo prestigio que la del flaneur, en primer lugar porque la mera idea de que una mujer viaje, vague o ande sola atenta (todavía) contra los prejuicios de mucha gente. Es por ello que cada vez que conozco historias de mujeres que viven estas experiencias sé que son resultado de haberse enfrentado a,

1 Todas las citas pertenecientes a Lo contrario de mirar corresponden a Pellicer Vázquez (2019), por lo cual sólo se anota el número de página. 
por lo menos, un par de personas que hicieron de todo para impedirlo. En Lo contrario de mirar, Ana Pellicer nos regala los relatos "La enfermedad es un invento de los gringos" y "Delirio habanero", pequeñas crónicas de mujeres que emprenden una travesía solas. En lugar de dejarse vencer por el miedo, estas viajeras toman el temor a lo desconocido y lo hacen parte de su aventura: "Pensaba en cómo de infeliz había sido cuando tenía ante sí solo claridades y cuartos supuestamente iluminados" (99).

"Yo quiero creer en la necesidad de llevar cicatrices" (47), declara con firmeza y a manera de mantra la protagonista del relato "Semántica de la cicatriz", ante el cuerpo dañado de un ser querido. Pronto nos damos cuenta de que esta forma de ver la vida no es privativa de dicho personaje: la autora también comparte esta filosofía y la extiende a toda su obra. Descubrimos, entonces, que la prosa de Ana Pellicer no tiene empacho en mostrar sus costuras ni sus remaches, al contrario, se regodea en ellos. Es por eso que, en sus relatos, la escritora no busca ocultar sus obsesiones, su formación literaria ni su feminismo, desafiando así la convención de que la literatura tiene que estar separada de la política. Prueba de ello es el último relato, "Post", un posicionamiento en clave de manifiesto. Se trata del más lúdico de los textos de la compilación: con un toque de humor e ironía, una voz en primera persona se encarga de desmontar varias categorías que en alguna época ofrecieron claridad, pero que ahora, tras el prefijo "post-", traslucen todas sus contradicciones. Desfilan, por ejemplo, 'postfranquismo', 'postfeminismo', 'postfamilia' y hasta 'postmemoria'. Esta última le hace exclamar: "irecordar qué? ipelear por qué? [...] Para qué recordar a Machado pudiendo ser ciberpunk" (166). La estructura de esta narración apela a lo experimental y quizá a la reescritura, por lo que uno bien podría seguir completando la lista.

El horror al vacío también forma parte de las preocupaciones de los personajes de Lo contrario de mirar. Uno de ellos, ante la conmoción de ver desvanecerse a su amante, alcanza a decir: "Pero no quiero ni frío ni silencio, quiero muchas palabras que me entretengan. El silencio me hace sentir vértigo y ser rehén de todas tus palabras me protege" (48). El lenguaje resuena desde el principio hasta el final cuando en otro relato la voz narrativa, también de cara a la posibilidad de perder a un ser querido, exclama con fervor: "Por eso voy a pelearle a la desmemoria y a reemplazar la memoria. ¿O sostenerla? Juntaré todas nuestras palabras. El amor ahora es hablar y no callar. Desgarrarme. Es ya lo único que puedo hacer por ti. Por nosotros" (145). 
de la memoria eso que ya no puede permanecer oculto pero que, paradójicamente, sólo ve la luz para sumergirse de nuevo en otra mentira, la de la literatura; o bien, la voluntad de atar, en boca de uno de sus personajes, "cabos sueltos que pueden llegar a creer que ahora entienden algo en la desnudez de la impostura” (86). Su lectura nos deja con la certeza de que lo que no cabe en la memoria, cabe en la literatura.

Ana Pellicer Vázquez crea un universo narrativo en el que sus personajes, especialmente los femeninos, viven el amor y el deseo desaforadamente, deciden y se hacen responsables, se permiten ser valientes. La autora construye, pues, dentro de su escritura, un lugar seguro para todas al que da gusto regresar.

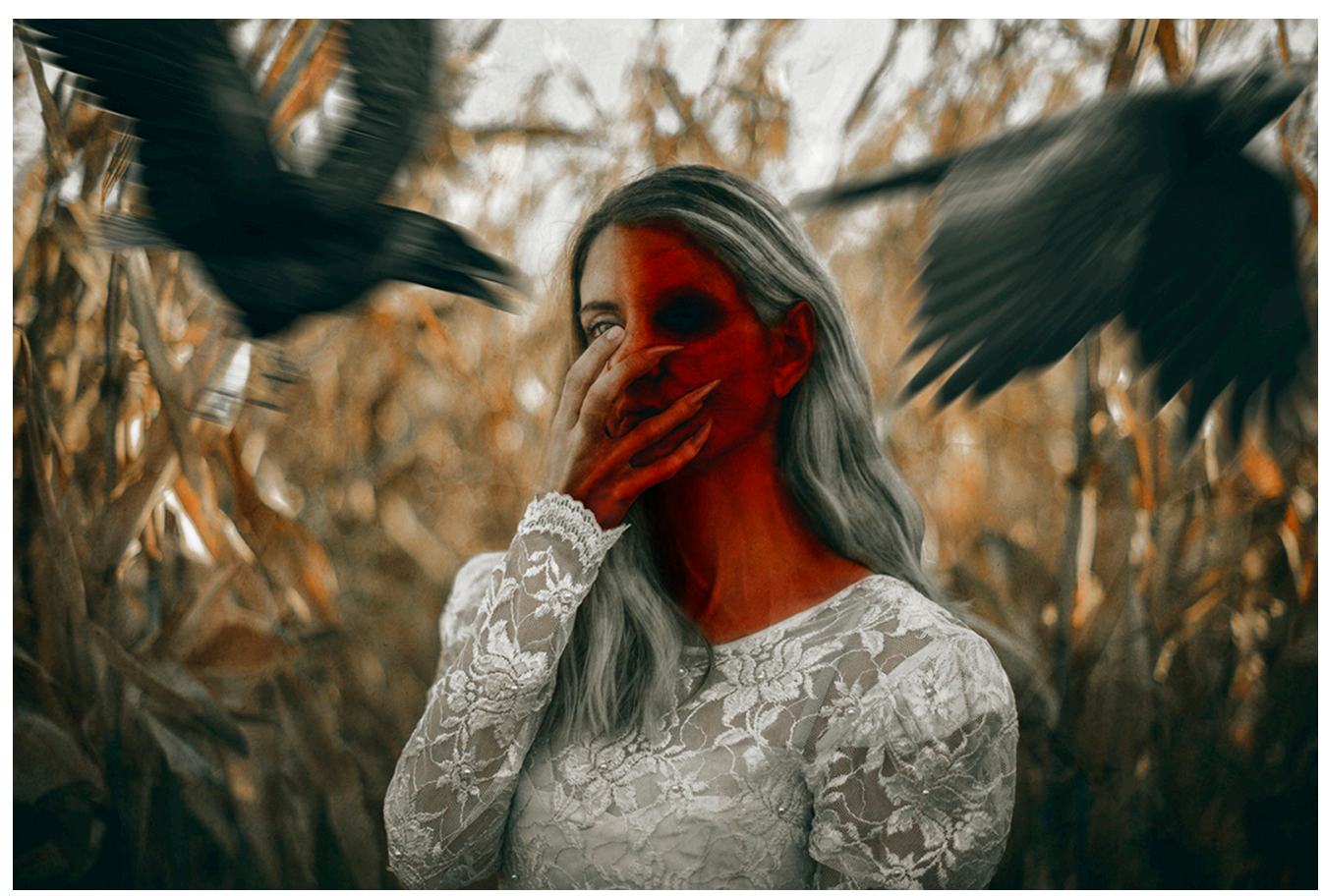

Demons (2020). Fotografía Fine Art: Frank Diamond.

Prohibida su reproducción en obras derivadas.

Stephanie Cortez Conde. Licenciada en Letras Latinoamericanas por la Universidad Autónoma del Estado de México (UAEM), México. Especialista en procesos editoriales con énfasis en la producción de revistas científicas latinoamericanas del ámbito de las artes y las humanidades. 